\title{
Improved cultivation of gdhA derivative Pasteurella multocida B:2 for high density of viable cells through in situ ammonium removal using cation-exchange resin for use as animal vaccine
}

\begin{abstract}
Pasteurella multocida serotype B:2 is the causative agent of hemorrhagic septicemia, a fatal disease of cattle and buffaloes. A live attenuated vaccine, gdhA derivative $P$. multocida B:2 mutant, was created to defeat the disease. During the cultivation of $P$. multocida B:2 mutant, substantial amount of ammonium was accumulated in the culture, which greatly inhibited the growth of this bacterium. The feasibility of using integrated cultivation with in situ removal of ammonium by cation-exchange resin for the improvement of growth and viability of $P$. multocida cells was investigated. The ability of various cation-exchange resins, which include Amberlite IRC86, Amberlite IR120 H, and Dowex DRG8 H, to selectively adsorbed ammonium was first investigated using sorption isotherm experiments. Amberlite IRC86 has the highest ability for ammonium adsorption. The incorporation of $10 \mathrm{~g} / \mathrm{L}$ of Amberlite IRC86 resin into the shake flask culture $(100 \mathrm{~mL})$ of $P$. multocida B:2 mutant, improved the final viable cell concentration $\left(7.2 \times 10^{10} \mathrm{cfu} / \mathrm{mL}\right)$ by about 13 -fold compared to that obtained in cultivation without resin $\left(5.5 \times 10^{9} \mathrm{cfu} / \mathrm{mL}\right)$. In cultivation with Amberlite IRC86 resin, approximately $41 \%$ of the ammonium accumulated in the culture was removed.
\end{abstract}

Keyword: gdhA derivative Pasteurella multocida B:2; Cell viability; Removal; Ammonium; Cation-exchange resin 